\title{
Erratum to: Population-level variation in juvenile brown trout growth from different climatic regions of Norway to an experimental thermal gradient
}

\author{
Kim Magnus Bærum • Leif Asbjørn Vøllestad • \\ Peter Kiffney • Alice Rémy • Thrond Oddvar Haugen
}

Published online: 16 November 2016

C) Springer Science+Business Media Dordrecht 2016

\section{Erratum to: Environ Biol Fish \\ DOI 10.1007/s10641-016-0533-6}

The original version of this article unfortunately contained a mistake. Leif Asbjørn Vøllestad's surname was incorrectly presented as Vøllestada. The original article was corrected.

The online version of the original article can be found at http://dx.doi.org/10.1007/s10641-016-0533-6.

K. M. Bærum

Norwegian Institute for Nature Research, Fakkelgården, NO-2624, Lillehammer, Norway

K. M. Bærum • P. Kiffney · A. Rémy · T. O. Haugen Faculty of Applied Ecology and Agricultural Sciences, Campus Evenstad, Hedmark University College, P. O. Box 400,

2418 Elverum, Norway

K. M. Bærum $(\bowtie) \cdot$ L. A. Vøllestad

Centre for Ecological and Evolutionary Synthesis (CEES),

Department of Bioscience, University of Oslo, P. O. Box 1066, 0316 Blindern, Oslo, Norway

e-mail: kim.barum@nina.no

P. Kiffney

National Oceanic and Atmospheric Administration, National Marine Fisheries Service, Northwest Fisheries Science Center, Fish Ecology Division, Watershed Program, Building B,

Mukilteo, WA 98275, USA

T. O. Haugen

Department of Ecology and Natural Resource Management, Norwegian University of Life Sciences, P. O. Box 5003, NO-1432, Aas, Norway 